This item was submitted to Loughborough's Research Repository by the author.

Items in Figshare are protected by copyright, with all rights reserved, unless otherwise indicated.

\title{
Prediction of steel fibre reinforced concrete under flexure from an inferred fibre pull-out response
}

PLEASE CITE THE PUBLISHED VERSION

PUBLISHER

Springer Netherlands

LICENCE

CC BY-NC-ND 4.0

REPOSITORY RECORD

Prudencio, Luiz, Simon A. Austin, Peter A. Jones, Hugo Armelin, and Peter J. Robins. 2019. "Prediction of Steel Fibre Reinforced Concrete Under Flexure from an Inferred Fibre Pull-out Response". figshare. https://hdl.handle.net/2134/3900. 
This item was submitted to Loughborough's Institutional Repository (https://dspace.lboro.ac.uk/) by the author and is made available under the following Creative Commons Licence conditions.

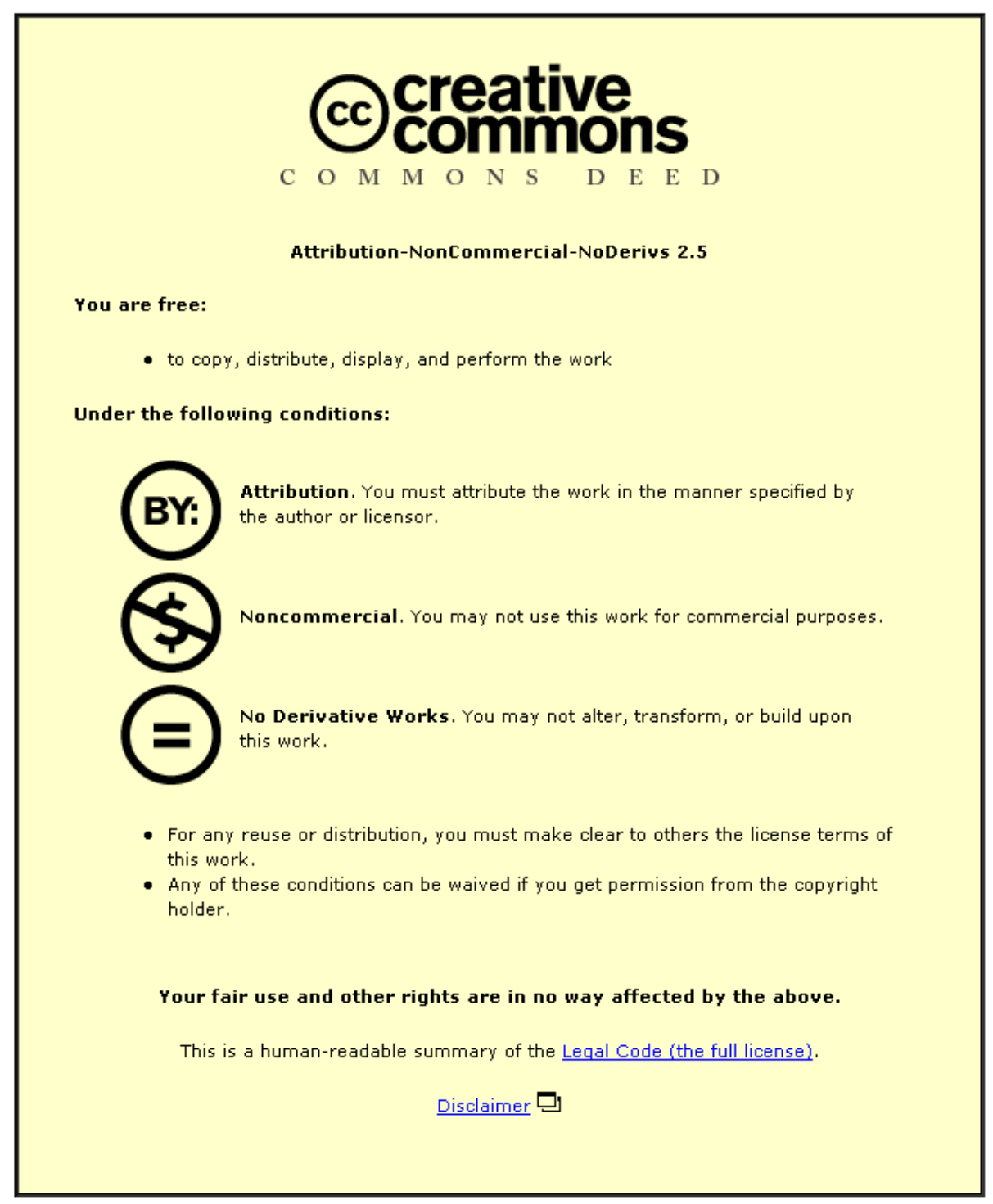

For the full text of this licence, please go to: http://creativecommons.org/licenses/by-nc-nd/2.5/ 


\title{
Prediction of steel fibre reinforced concrete under flexure from an inferred fibre pull-out response
}

\author{
Luiz Prudencio Jr. ${ }^{1}$, Simon Austin ${ }^{2}$, Peter Jones ${ }^{3}$, Hugo Armelin ${ }^{4}$ and Peter Robins ${ }^{5}$ \\ (1) Dept of Civil \& Building Engineering, University of Santa Catarina, Brazil \\ (2) Dept of Civil \& Building Engineering, Loughborough University, UK \\ (3) Adept Management Ltd, UK \\ (4) Lafarge Ltd, Brazil \\ (5) Dept of Civil \& Building Engineering, Loughborough University, UK
}

\begin{abstract}
Steel fibre-reinforced concrete (SFRC) is being used in a variety of structural applications, yet there is still considerable debate how to express and evaluate flexural toughness for design purposes. This is holding back the material's development as a permanent structural material. Existing beam and slab test methods have problems with variability or their application in structural design. Furthermore, existing models of SFRC flexural behaviour do not fully capture what happens at the cracked section in terms of the fibre-matrix interactions. Typical of these approaches is the modelling of the tension zone from single fibre pull-out tests, which is problematic in measurement of the load-displacement relationship, the interaction of groups of fibres and the extensive testing required to cover all permutations of fibre geometry.

An alternative approach is proposed where the average pull-out response of the fibres bridging the cracked zone is inferred from flexural beam tests. The characteristic load versus crack-mouth opening displacement behaviour for a particular fibre concrete then forms part of the stress and strain/displacement profile in a flexural analysis to predict moment capacity in a design calculation. The model is explained together with its validation by comparing the predicted load-displacement response for a range of fibre volumes in sprayed and cast SFRC. It is concluded that the analysis of beam load/deflection curves to infer the fibre pull-out response is a viable approach. It offers a promising solution to the need for a flexural design model combined with a practical method of characterizing the tensile contribution of steel fibres.

RÉSUMÉ

Le béton en acier de fibre-reinfornced (SFRC) est employé dans une variété d'applications structurales, pourtant il reste discussion considérable comment exprimer et évaluer la dureté flexural pour la conception. Ceci tient en arrière le développement du matériel comme matériel structural permanent. Les méthodes existantes d'essai de faisceau et de galette ont des problèmes avec la variabilité ou leur application dans la conception structurale. En outre, les méthodes existantes de comportement flexural de SFRC ne capturent pas entièrement ce qui se produit à la section criquée en termes d'interactions de fibre-matrice. Typique de ces approches est modeler de la zone de tension des essais simples de dégagement de fibre, ce qui est problématique dans la mesure du rapport de charge-déplacement, l'interaction des groupes de fibres, et l'essai étendu requis pour couvrir toutes les permutations de la géométrie de fibre.

On propose une approche alternative où la réponse à coulisse moyenne des fibres jetant un pont sur la zone criquée est impliquée des essais flexural de faisceau. La charge caractéristique contre le comportement de déplacement d'ouverture de fente-bouche pour un béton particulier de fibre fait alors partie de l'effort et de profil de contraint/déplacement dans une analyse flexural pour prévoir la capacité de moment dans un calcul de conception. Le modèle est expliqué ainsi que sa validation en comparant la réponse prévue de chargedéplacement pour une gamme des volumes de fibre dans pulvérisé et la fonte SFRC. On le conclut que l'analyse des courbes du faisceau charge/débattement pour impliquer la réponse à coulisse de fibre est une approche viable. Il offre une solution prometteuse à la nécessité pour un modèle flexural de conception combiné avec une méthode pratique de caractériser la contribution de tension des fibres en acier.
\end{abstract}

\section{INTRODUCTION}

Steel fibre-reinforced concrete (SFRC) has been used increasingly in recent years, primarily for tunnel linings, industrial floor slabs and similar applications. Although there is no question about the contribution of fibres to enhance concrete flexural toughness, the question of how to evaluate it and express it as a useful parameter for design purposes is still under debate. A number of test methods have been proposed to evaluate SFRC toughness, but all have significant problems associated with either the variability of the results or their application in structural design calculations ${ }^{1}$. Furthermore, in spite of some attempts made at modelling the flexural behaviour of steel fibre reinforced concrete, no one model has been able to fully explain what actually happens at the critical cracked section in terms of the fibre-matrix interactions. Consequently, a current limitation on the structural use of the material is a distinct lack of accepted design methods, which has resulted in a lack of confidence in its use as a permanent structural material. 
Some of the proposed methods for modelling the flexural post-crack behaviour of SFRC are based on the equilibrium of forces at the cracked section. The tensile strength is a composite action between that resisted by the cementitious matrix and that supported by the fibres bridging the crack. To implement this kind of model, it is clearly necessary to estimate the force transmitted by the fibres, which occurs through the bond at the interface with the surrounding matrix. The components of bond can be classified as: the physical and/or chemical adhesion between fibre and matrix; the frictional resistance; the mechanical component (associated with a particular geometry of the fibre be it deformed, crimped, or hooked); and the fibre-to-fibre interlock ${ }^{2}$. To deal with this, several authors ${ }^{3,4}$ have determined the average response of the load transmitted by the fibres through the cracked region from pull-out tests of single fibres. Some problems arise with this approach, namely: the number and position of the fibres bridging the crack is not precise, the load supported by each fibre depends on the crack opening displacement (a function of the specimen displacement), the orientation of the fibre and the embedment length.

To overcome such problems, the authors have examined various permutations of fibre orientation and embedment length and determined the number of fibres using theoretical equations ${ }^{3}$ and experimental data ${ }^{4,5}$. This kind of

approach, however, has some shortcomings. For each new situation (fibre type and matrix) it is necessary to undertake single fibre pull-out tests (with varying fibre orientation and embedment length) that are costly and time consuming.

It is unclear whether a fibre, pulled-out of a matrix in a direct tension test, is representative of the behaviour of multiple fibres in concrete under flexure. Furthermore, the orientation of fibres and their interface with the cementitious matrix depends on the concrete placing method used in the field such as vibration or spraying. One solution proposed by Casanova and Rossi ${ }^{6}$ and by RILEM ${ }^{7}$ recommends the use of a uniaxial tension test on a SFRC specimen taken in-situ. The specimens are cored to ensure compliance with the distribution of the fibres and the quality of the matrix. However, besides the difficulties of undertaking this kind of test, doubts about its efficacy in representing the actual behaviour of the fibres being pulledout under flexure still remain.

An alternative approach is proposed in this paper where the average pull-out response of the fibres bridging the cracked zone is inferred from the results of flexural tests. This characteristic load versus crack-mouth opening displacement (CMOD) behaviour for a particular fibre concrete can then form part of the stress and strain/displacement profile in a flexural analysis to obtain the moment capacity.

\section{MODEL CONCEPTS}

The concept of the model is illustrated in Figure 1, which shows an idealised representation of a crack at the critical section of a steel fibre reinforced concrete beam under flexural loading, together with the corresponding stress-block diagram. Using this concept, the stresses (and resultant forces) that develop at the critical section can be represented by three distinct zones: (1) compression zone; (2) an uncracked tension zone; and (3) a cracked tension zone. The cracked tension zone can be further represented by three sub-zones: an aggregate bridging zone - resulting from matrix micro-cracking which initiates fibre-matrix debonding; a fibre bridging zone - in which the fibres are partially pulled out from the matrix; and a traction free zone - in which the fibres are completely pulled out from the matrix. By considering the forces across the critical section in this way the flexural capacity of the critical section can be related to the following principal parameters:

- the concrete compressive stress-strain relationship

- the concrete tensile stress-strain relationship

- the concrete tensile strain-softening relationship

- the average single fibre pull-out load versus crackwidth (CMOD) relationship

- the number and distribution of the fibres bridging the cracked section

- the strain profile (and associated neutral axis position) of the uncracked beam and the crack-width profile of the cracked beam in relation to mid-span deflection

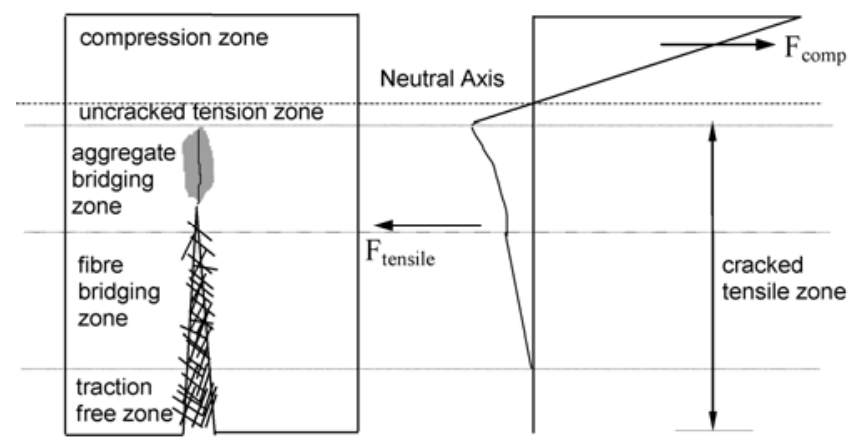

Figure 1 Zones of behaviour and simple stress block of a steel fibre reinforced concrete beam under flexure

If relationships for these parameters can be established, then the shape and magnitude of the stress-block diagram can be predicted for a given beam deflection. Hence, providing the internal force equilibrium of the section is satisfied, the flexural moment capacity of the beam can be computed for a given beam deflection.

To obtain the profile of the curve relating the average singlr fibre pull-out strength to the CMOD from a flexural test it is necessary to make some assumptions. In a standard four point bending test the elastic deflections of the specimen are of the order of hundredths of a millimetre while the actual region of interest in the load versus 
deflection diagram for calculating the $\mathrm{ASTM}^{8}$ or $\mathrm{JSCE}^{9}$ toughness indices lies in a range of deflections 10 to a 100 times greater than those at first crack (up to $2 \mathrm{~mm})^{3}$. This indicates that rigid body motion of the two broken halves of the specimen is by far the dominant mechanism. Consequently the failure mode commonly observed, characterised by a main failure crack at mid-span, has clear resemblance with a plastic hinge, a phenomenon suggested by other researchers ${ }^{10,11}$.

Nevertheless, the question of how to determine the size and position of the hinge remains. Armelin and Banthia ${ }^{3}$ proposed a simple solution assuming the axial compressive strain at the top-most fibre of the specimen at mid-span $\left(\varepsilon_{0}\right)$ as a function of the rotation angle. The total axial shortening $\left(\Delta_{o}\right)$ can be computed from Figure 2 as:

Error! Objects cannot be created from editing field codes.

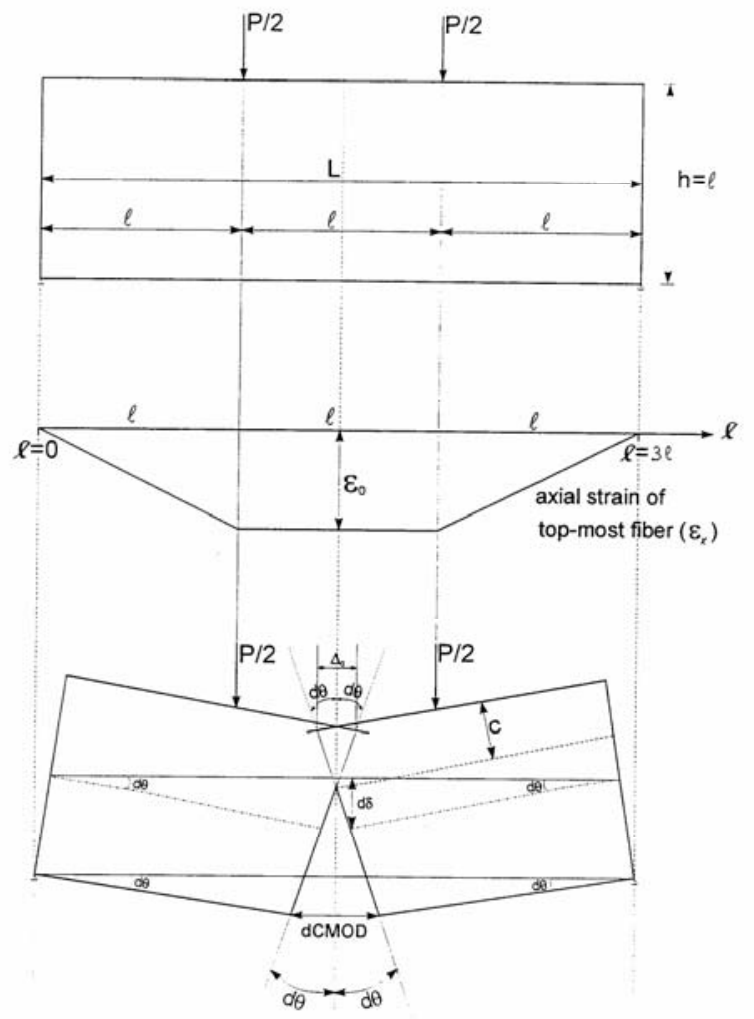

Figure 2 - Mode of failure assumed for calculation of midpoint deflection $(\delta)$

The position of the neutral axis, measured from the top of the specimen ( $c$ - centre of rotation) can be calculated by satisfying the equilibrium of forces in the cracked section of the prism at mid-span. The incremental rotation angle $(d \theta)$ can be obtained from:

Error! Objects cannot be created from editing field codes.
The resulting increment in the deflection $(d \delta)$ and crackmouth opening displacement $(d C M O D)$ is given by:

Error! Objects cannot be created from editing field codes.

\section{Error! Objects cannot be created from editing field} codes.

The load $(\mathrm{P})$ can be obtained by satisfying moment equilibrium :

Error! Objects cannot be created from editing field codes.

The equilibrium moment $\left(M_{e}\right)$ can be computed from the individual moments generated by the force $\left(f_{i}\right)$ carried by each of the $\mathrm{N}$ individual fibres that are being pulled out, multiplied by their positions with respect to the neutral axis $\left(y_{i}\right)$, plus the moment generated by the concrete stresses $\left(\sigma_{c}\right)$. Considering the equilibrium of forces and moments gives:

\section{Error! Objects cannot be created from editing field} codes.

(6)

Error! Objects cannot be created from editing field codes.

As explained previously, the average curve can be determined by back analysis (ie through the average results of four point bending tests) instead of using an approach where it is necessary to test single fibres under tension to obtain an average curve relating the pull-out force to CMOD.. The typical shape of such a curve for hooked end fibres, based on the findings of various researchers, is shown in Figure 3.

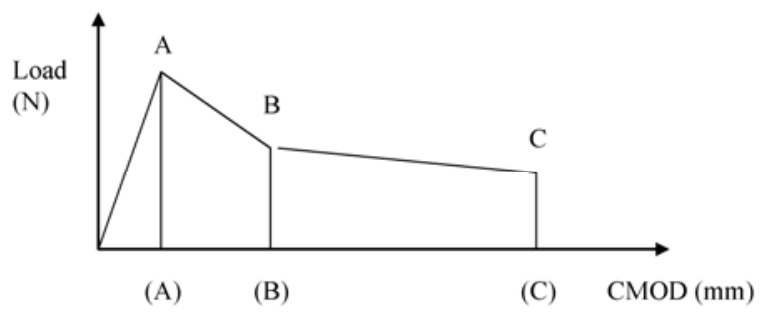

Figure 3 - Simplified curve representing the average pull-out response of a single fibre

The peak A is due to the presence of the hook ${ }^{2,3}$. After this, the load decreases gradually corresponding to the straightening of the hook end of the fibre phase. The line $\mathrm{BC}$ indicates the frictional pull-out stage in which the fibre is rigidly displaced from the matrix through its print and the pull-out resistance is supplied by decaying interfacial frictional stresses. Of course, the actual shape of the curve is not formed by straight line segments; this simplified shape is used to facilitate the determination of the load as a function of CMOD. 
To obtain such a curve, it is necessary to test a set of flexural specimens (four point load bending test recommended by $\mathrm{ASTM}^{8}$ or EFNARC ${ }^{12}$, for example) with the same type of fibre and matrix proposed for the actual structure. The load versus deflection (or CMOD) must be recorded. Using the average results of load supported by the beam at different deflections and the assumptions described previously, it is possible to calculate, by trial and error, the points $\mathrm{A}, \mathrm{B}$ and $\mathrm{C}$ of Figure 3 that leads to the best agreement with the curve obtained in the flexure tests. The average response of a single fibre can be obtained if a count is made of the number of fibres in the cracked cross-section of the specimen. Alternatively, the number of fibres $(\mathrm{N})$ can be estimated from the equation proposed by Romualdi and Mandel $^{13}$ and adapted by Mindess ${ }^{14}$ :

\section{Error! Objects cannot be created from editing field} codes.

where:

Error! Objects cannot be created from editing field codes. Number of fibres that cross a given cross-section of the concrete member Error! Objects cannot be created from editing field codes.

$\alpha=$ fibre orientation factor

Error! Objects cannot be created from editing field codes. Volume of fibre $/ \mathrm{m}^{3}$

Error! Objects cannot be created from editing field codes.Fibre cross section area

Error! Objects cannot be created from editing field codes. Fibre diameter

The fibre orientation factor $(\alpha)$ represents the average ratio of projected fibre length (in the tensile load direction) to actual fibre length, for all possible fibre orientations. Hence, its value is independent of fibre pull-out load but is dependent on a number of fibre distribution variables including boundary effects (imposed by the casting mould), specimen size and method of placement. Romualdi and Mandel $^{13}$ showed that it has a theoretical value of 0.41 for a random 3D fibre distribution. However, in this study a value of 0.5 was used as being more representative of the fibre distribution measured in cast SFRC beam specimens ${ }^{3 \text {, }}$ 15

\section{IMPLEMENTATION OF THE MODEL}

\subsection{Overview}

After determining the calculated average curve relating the pull-out response of a single fibre versus CMOD, it is possible to estimate the load bearing capacity of beams of different depths, widths, span and fibre content by determining the depth of the neutral axis that leads to the equilibrium of forces and moments at the cracked section at any given mid-span deflection. Following the general principles of Figure 1, the approach taken was to combine models of the concrete stress/strain relationships in compression and tension, with the fibre pull-out force relationship with crack opening. Figure 4 shows the superimposed block diagrams which summarise the conceptual assumptions of the proposed method, which is based on the model proposed by Robins et $\mathrm{al}^{16}$.

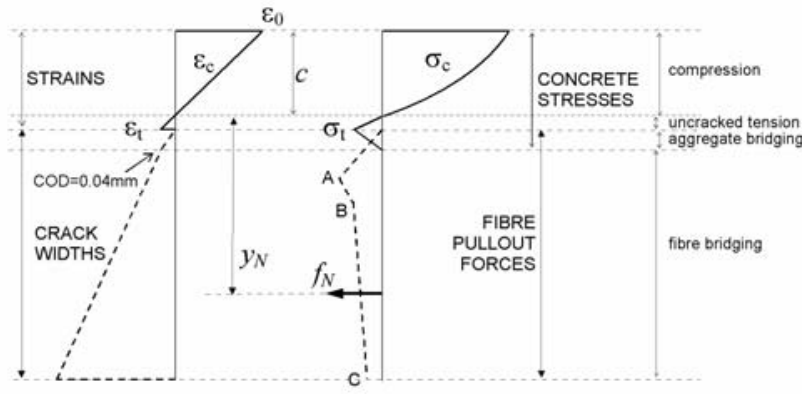

Figure 4 - Stress/strain and force/crackwidth blocks across the cracked section adopted in the model

The crack openings in the fibre bridging zone were calculated on the basis of rigid body motion (as per Figure 2 and related equations 1-7) i.e. with a projected origin at the neutral axis. The relationship in the small aggregate bridging zone was modified to reflect that in reality cracking starts to occur at the bottom of the un-cracked tension zone.

The overlap in concrete tensile stress with fibre pullout force reflects the use of the principle of superposition used in the modelling to add the concrete behaviour to that of the fibres during pullout. This enables the use of existing models for the concrete stress/strain relationship (including softening) and fibre pullout data (equations 9-13).

A spreadsheet was developed (in MS Excel) to calculate the depth of the neutral axis, at any deflection, capable of accomplishing these two requirements. The load/deflection curve was calculated at deflection increments of $0.2,0.5,1$, 2 and $3 \mathrm{~mm}$, by conducting trial and error calculations to achieve equilibrium.

\subsection{Compression zone}

Under compression, concrete was assumed to behave according to a parabolic stress-strain relationship as proposed by the CSA code ${ }^{17}$ :

where:Error! Objects cannot be created from editing field codes.

\subsection{Un-cracked tensile zone}

In the proposed method, concrete is assumed to behave elastically under tension, with a modulus of elasticity (Error! Objects cannot be created from editing field codes.) estimated from its cylinder compressive strength (Error! Objects cannot be created from editing field codes.) using a modification of the expression given by CSA (1984) $\operatorname{Code}^{17}$ : 
Error! Objects cannot be created from editing field codes. (in $\mathrm{MPa}$ )

The maximum flexural tensile stress of the concrete is estimated by one of the following expressions:

Error! Objects cannot be created from editing field codes. (Model 1)

or

Error! Objects cannot be created from editing field codes. (Model 2)

\subsection{Aggregate bridging zone}

A semi-theoretical stress/crack-width relationship ( $\sim \mathrm{w}$ curve) was derived, for crack-widths up to $0.04 \mathrm{~mm}$, using the law of mixtures. This was achieved by combining a theoretical tensile $\mathrm{w}$ curve for the plain concrete matrix with the inferred average fibre pull-out response (Fig. 3) converted to stress.

The tensile stress in the concrete under strain-softening regime (Error! Objects cannot be created from editing field codes.) is taken to decrease exponentially up to an additional crack opening of $0.04 \mathrm{~mm}$, according to experiments reported by Gopalaratnam and Shah ${ }^{18}$. The expression used in this case was:

Error! Objects cannot be created from editing field codes.

where:

Error! Objects cannot be created from editing field codes.

Error! Objects cannot be created from editing field codes.crack opening $(\mathrm{mm})$

Error! Objects cannot be created from editing field codes.

\subsection{Fibre bridging zone}

The fibre bridging forces were determined by relating the average single fibre pull-out curve (Fig 3) to the crackwidth profile at each mid-span deflection considered, and then combining the resulting single fibre pull-out loads with the fibre density data obtained from manual fibre counting or theoretically from equation 8 .

\section{VALIDATION OF THE MODEL}

\subsection{Application of the proposed model}

A practical example to show the application of the proposed methodology is presented in this section, using data from Jones et $\mathrm{al}^{4}$.

In order to characterize the pull-out versus crack opening curve, the load/deflection curves from tests undertaken on seven $75 \mathrm{~mm}$ deep unnotched beams containing $40 \mathrm{~kg} / \mathrm{m}^{3}$ of
$30 \mathrm{~mm}$ length and $0.5 \mathrm{~mm}$ diameter hooked steel fibres were initially analysed (Figure 5).

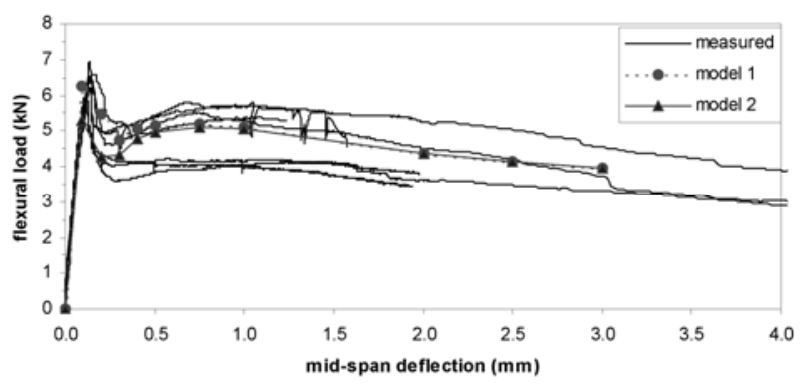

Figure 5 - Experimental curves used to adjust the model and the correspondent resulting theoretical curve obtained $-75 \times 100 \mathrm{~mm}$ beams. Fibre content $40 \mathrm{~kg} / \mathrm{m}^{3}$

The beam width was $100 \mathrm{~mm}$. The resulting theoretical pull-out versus crack opening curve (Figure 6) was obtained from a trial and error back analysis in a simple computer program which allowed rapid convergence on a pull-out load/CMOD relationship that produced a theoretical flexural behaviour in good agreement with the experimental results.

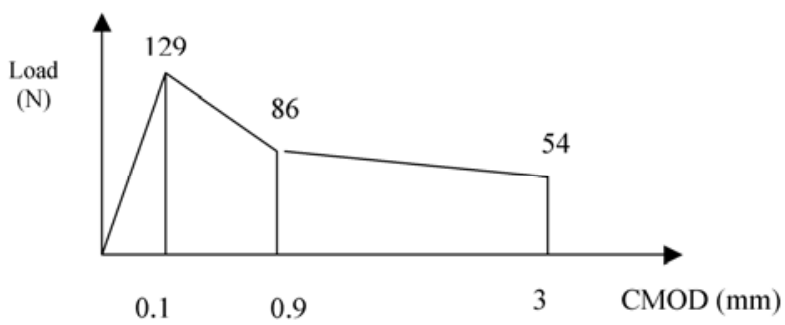

Figure 6 - Theoretical fibre pull-out versus crack opening curve

Figure 5 also shows the resulting calculated load/deflection curve. In Table 1 , a comparison is made between the theoretical and average experimental results at four deflections, which indicates good agreement.

The theoretical fibre pull-out curve of Figure 6 was then validated by applying it to beams of different geometries and fibre contents. Comparisons between the theoretical and experimental load/deflection data of seven combinations are presented in Table 2. Figures 7 to 10 show the load/deflection curves of four of these combinations $\left(26-66 \mathrm{~kg} / \mathrm{m}^{3}\right.$ of fibres).

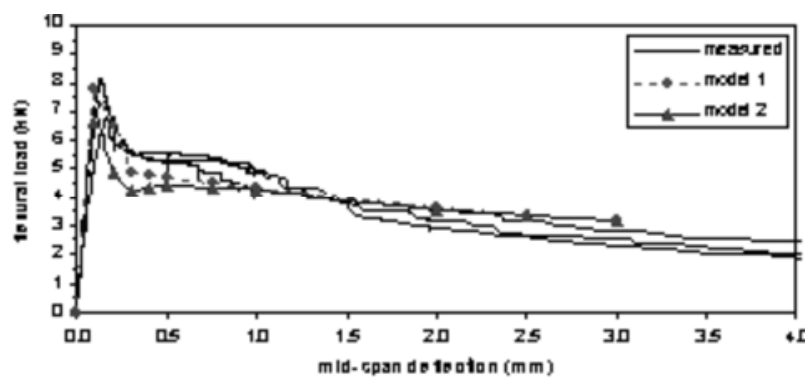


Figure 7 - Experimental and theoretical curves $75 \times 125 \mathrm{~mm}$ sprayed concrete, $26 \mathrm{~kg} / \mathrm{m}^{3}$

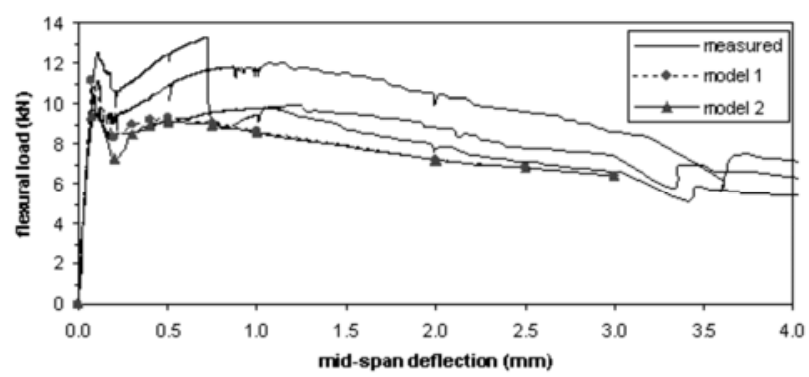

Figure 8 Experimental and theoretical curves - 100x100mm cast fibre beams, $40 \mathrm{~kg} / \mathrm{m}^{3}$

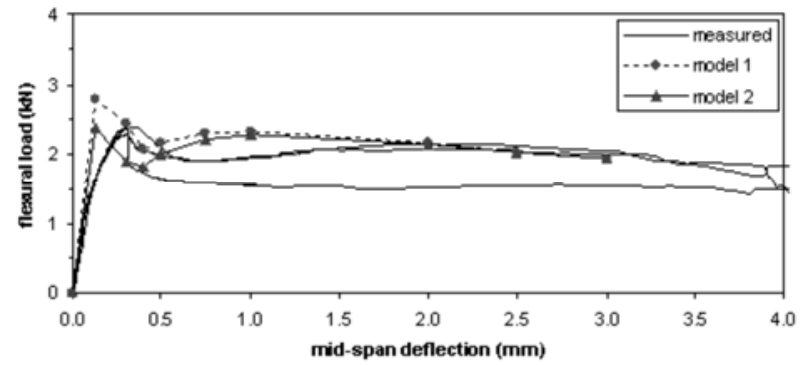

Figure 9 Experimental and theoretical cures $50 \times 100 \mathrm{~mm}$ cast fibre beams, $40 \mathrm{~kg} / \mathrm{m}^{3}$

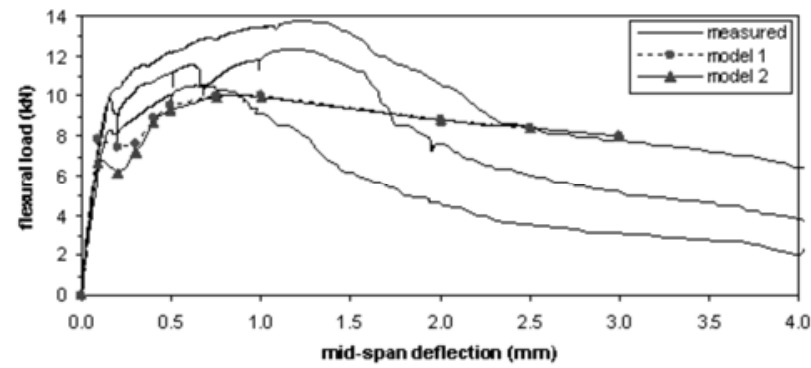

Figure 10 Experimental theoretical curves - 75x125mm sprayed concrete beams, $66 \mathrm{~kg} / \mathrm{m}^{3}$

\subsection{Analysis}

The comparison presented in Table 2 shows, in most cases, a good agreement between the experimental results and those obtained by the application of the model.

For the sprayed concrete beams (Figures 7 and 10) the theoretical curve under-estimates the loads at the lower deflections and over-estimates them at larger deflections. This behaviour could be a result of a preferential fibre orientation or even of a modification in the micro-structure of the fibre-matrix interface due to the spraying process used to manufacture the beams.
Comparing the results obtained from Model 1 and Model 2 , the latter leads to slightly lower load responses at low deflection values but at deflections below $0.5 \mathrm{~mm}$ Model 1 is generally a better fit.

For the cast concrete beams with the highest fibre content $\left(80 \mathrm{~kg} / \mathrm{m}^{3}\right)$ the load capacity of the beams was overestimated, especially at large deflections. This may be caused by a reduction in the pull-out capacity of the fibres due to their closer spacing i.e. the fibres start to interfere with each other. An alternative explanation is that the these samples had a non-random 3D fibre orientation, making the assumed $\alpha$ value of 0.5 inappropriate. It was possible to test the latter idea because the broken cross-sections of these beams were inspected and the fibre distribution calculated from a manual fibre count ${ }^{158}$. This produced $\alpha$ values of $0.44,0.38$ and 0.52 respectively for the last three $\left(80 \mathrm{~kg} / \mathrm{m}^{3}\right)$ concrete mixes listed in Table 2 . It can be seen that the lower values of $\alpha$ are consistent with the high overestimates of load capacity. To test this hypothesis, the fibre pull-out curve (Figure 6) was recalculated for each of these mixes using its calculated $\alpha$ value and Models 1.The results obtained are presented in Table 3 and Figures 11 to 13 .

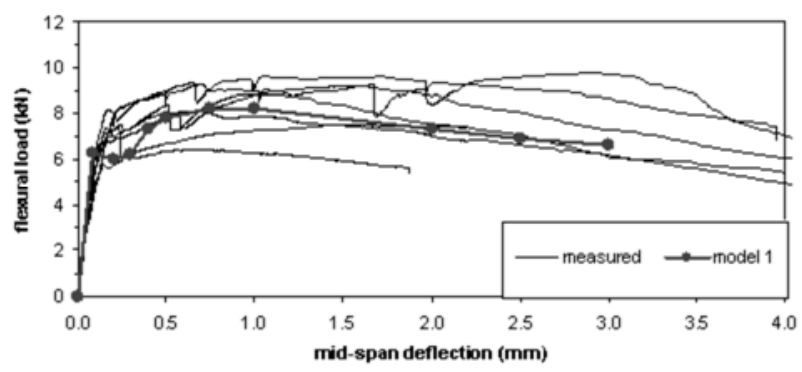

Figure 11 - Experimental and theoretical curves $-75 \times 100 \mathrm{~mm}$ cast fibre beams, $80 \mathrm{~kg} / \mathrm{m}^{3}(\alpha=0.44)$

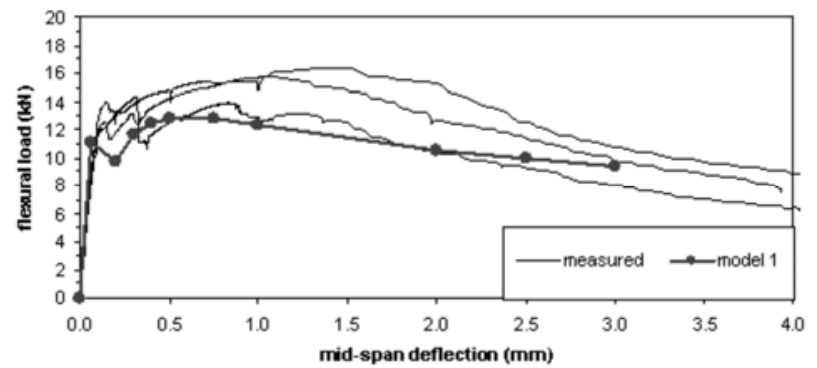

Figure 12 - Experimental and theoretical curves - 100x100mm cast fibre beams, $80 \mathrm{~kg} / \mathrm{m}^{3} \quad(\alpha=0.38)$ 


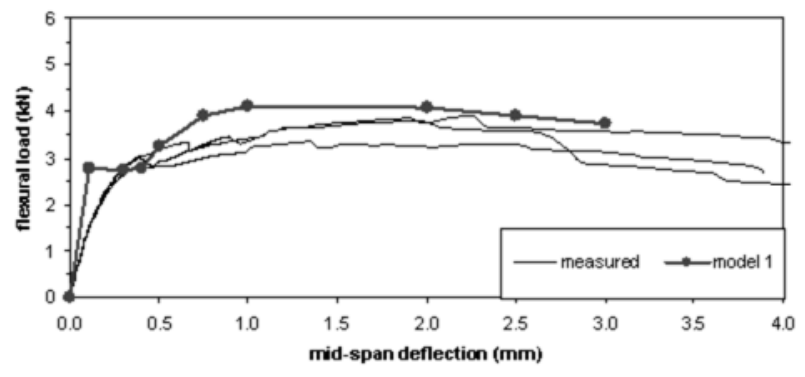

Figure 13 - Experimental and theoretical curves $-50 \times 100 \mathrm{~mm}$ cast fibre beams, $80 \mathrm{~kg} / \mathrm{m}^{3} \quad(\alpha=0.52)$

These curves show a better agreement with the experimental results and suggest that predictions from the Model can be improved if the spatial distribution of the fibres is taken into consideration in specimens where there is likely to be some alignment of fibres, for example at high fibre contents or where deeper moulds reduce the otherwise preferential effects of confinement ${ }^{156}$.

Further validation of the proposed model comes from the good agreement between the theoretical (with $\alpha=0.5$ ) and experimental values of the depth of the neutral axis at specific beam deflections as can be seen in Table 4. It should be noted that the experimental values were averages obtained from beams with a range of fibre contents. The higher discrepancy with the $50 \mathrm{~mm}$ deep beams could be due to imprecision in the determination of the experimental values because of the difficulties in measuring compressive strains with strain gauges when the neutral axis is very close to the top of the beam.

Although not covered in this paper, the resulting single-fibre pull-out curve shown in Figure 6 is further discussed, in the context of comparisons with similar pullout data reported elsewhere in the literature, in reference 3.

\section{CONCLUSIONS}

A new approach is proposed for modelling the flexural behaviour of SFRC using a single fibre pull-out response curve inferred from conventional four-point load beam tests. The key merits of the approach are: (a) its simplicity in formulation; (b) its use of conventional principles of mechanics; (c) its use of principal parameters, which on the whole can be determined theoretically without the need for extensive laboratory testing; (d) its use of (and link with) test data from established flexural toughness test methods for steel fibre reinforced concrete (i.e. four point load beam tests) and (e) its potential for incorporating into a design rationale for steel fibre reinforced concrete.

A good agreement was obtained between the experimental and calculated load/deflection curves derived from the proposed model for the range of mixes considered, as measured by the beam load capacity and depth of neutral axis. It is concluded that the analysis of beam load/deflection curves to calculate the fibre pull-out response is a viable approach. It offers a promising solution to the need for a flexural design model combined with a practical method of characterizing the tensile contribution of steel fibres. We should be cautious, however, in extending the concept to significantly different types of fibre reinforced concrete, e.g. with higher fibre volumes (i.e. greater than $80 \mathrm{~kg} / \mathrm{m}^{3}$ ), with very short fibres, ultra-high compressive strength or synthetic fibres.

Furthermore, it has been shown that it is adequate to use a theoretical random orientation factor $\alpha$ of 0.5 to model the response of cast steel fibre reinforced concrete in most situations. However, in cases where the production process, fibre volume and confinement effects combine to reduce $\alpha$, better predictions could be made if a manual count of the fibres is made at the cracked section, although this complicates the experimental procedure.

Further work should be conducted to clarify the reason for the discrepancies highlighted between the experimental and theoretical neutral axis depth for shallow beams (i.e. less than $50 \mathrm{~mm}$ ). In addition the validity of the approach for beam specimens of different geometries should also be investigated, especially with the low span-depth beams conforming to ASTM C-1018 ${ }^{8}$ that predominate in laboratory testing.

\section{REFERENCES}

[1] 1PRUDÊNCIO JR, L.R; AUSTIN, S.A., 'Test methods for evaluation of steel fibre reinforced concrete under flexure', paper in preparation.

[2] ALWAN, J.A; NAAMAN, A.E.; GUERRERO, P. 'Effect of mechanical clamping on the pull-out response of hooked steel fibers embedded in cementitious matrices' Concrete Science and Engineering, 1 ( March) (1999) 15-25.

[3] ARMELIN, H. S.; BANTHIA N. 'Predicting the flexural postcracking performance of steel fiber reinforced concrete from the pullout of single fibers' ACI Materials Journal, 94 (1), (1997) 18-31.

[4] JONES, P. A.; ROBINS, P. J. ; AUSTIN, S. A. 'Predicting the flexural load-deflection response of steel fibre reinforced concrete from fibre pull-out and distribution data' in preparation to be submitted to Materials and Structures (2005)

[5] ROBINS, P; AUSTIN, A. AND JONES, P., 'Pull-out behaviour of hooked steel fibres', Materials and Structures 35 (2002) 434-442.

[6] CASANOVA, P.; ROSSI, P. 'Analysis of metallic fibrereinforced concrete beams submitted to bending' Materials and Structures 29 (4) (1996) 354-361.

[7] RILEM TC 162-TDF. 'Recommendations of RILEM TC 162TDF: Test and Design Methods for Steel Fibre Reinforced Concrete - Uni-axial tension test for steel fibre reinforced concrete.' Materials and Structures 34 (1), (2001) 3-6.

[8] ASTM C1018-92 . 'Standard Test Method for Flexural Toughness and First-Crack Strength of Fibre-Reinforced Concrete (Using Beam with Third-Point Loading)', ASTM Annual Book of Standards, Vol. 04.02, (ASTM, Philadelphia, 1992) $510-516$

[9] JCI Standards for Test Methods of Fibre Reinforced Concrete . 'Method of Test for Flexural Strength and Flexural Toughness of Fibre Reinforced Concrete (Standard SF4)', (Japan Concrete Institute 1983) 45-51. 
[10] RILEM TC 162-TDF: 'Test and design methods for steel fibre reinforced concrete', Materials and Structures. 35 (2002) 262278.

[11] ULFKJÆR, J., KRENK, S. AND BRINCKER, R., 'Analytical model for fictitious crack propagation in concrete beam', ASCE J. Engineering Mechanics 121(1) (1995) 7-15.

[12] EFNARC 'European Specification for Sprayed Concrete, European Federation of national associations of Specialist Contractors and Material Suppliers for the Construction Industry' (EFNARC, 1996.)

[13] ROMUALDI, J.P.; MANDEL, J.A. 'Tensile strength of concrete affected by uniformly distributed and closely spaced short lengths of wire reinforcement' ACI Journal, 61 (June) (1964) 657-670.

[14] MINDESS, S. 'Standard Testing', in 'High Performance Fiber Reinforced Composites 2'. Chapter 10. Edited by A.E. Naaman and H.W. Reinhardt (E\&FN Spon, London, 1996).
[15] ROBINS, P.J.; AUSTIN, S.A.; JONES, P.A. 'Spatial distribution of steel fibre in sprayed and cast concrete', Magazine of Concrete Research, 55 (3) (2003) 225-235.

[16] ROBINS, P.J.; AUSTIN, S.A.; JONES, P.A. 'Flexural strength modelling of steel fibre reinforced sprayed concrete'. in 'Sprayed Concrete Technology' (E\&FN Spon, London, 1996) 107-114.

[17] CANADIAN STANDARDS ASSOCIATION 'Design of concrete structures for buildings (CAN3-A23.3-M84)', (Canadian Standards Association, Rexdale, Canada, 1984) 281.

[18] GOPALARATNAM, V.S.; SHAH, S.P. 'Softening response of plain concrete in direct tension', ACI Journal, 82 (3) (1985) 310-323. 